\title{
JENIS-JENIS PEMBELAJARAN JARAK JAUH BERBASIS TEKNOLOGI INFORMASI UNTUK PARA PENGUSAHA
}

\author{
Meiyanto Eko Sulistyo \\ Jurusan Informatika Fakultas Matematika dan IImu Pengetahuan Alam \\ Universitas Sebelas Maret, Surakarta, Indonesia \\ e-mail : mekosulistyo@uns.ac.id
}

\begin{abstract}
Distance learning is a learning strategy in which students and faculty interact via the Internet and delivered through video and audio conferencing, collaboration between students, and participate in a synchronous or asynchronous instruction. Types of distance learning based on information technology which is suitable for businesses, e-learning and instant messaging. Instant Messaging can save the cost of purchasing a computer server and leases office buildings, it will give birth to the concept of e-office (electronic-office).Distance learning based on information technology very useful for entrepreneurs, because it can save the cost of training.
\end{abstract}

Keywords: distance learning, e-learning, employers, instant messaging, information technology

Pembelajaran jarak jauh (distance learning) adalah sebuah strategi pembelajaran di mana mahasiswa dan dosen berinteraksi melalui Internet dan disampaikan melalui video dan audio conferencing, kolaboratif antara siswa, serta berpartisipasi dalam instruksi yang sinkron atau asinkron. Jenis pembelajaran jarak jauh berbasis teknologi informasi yang cocok untuk para pengusaha, yaitu e-learning dan instant messaging. Instant Messaging dapat menghemat biaya pembelian komputer server dan sewa gedung kantor, hal ini yang akan melahirkan konsep e-office (electronic-office). Pembelajaran jarak jauh (distance learning) berbasis teknologi informasi sangat bermanfaat sekali bagi para pengusaha, karena dapat menghemat biaya pelatihan.

Kata Kunci: distance learning, e-learning, pengusaha, instant messaging, teknologi informasi

\section{PENDAHULUAN}

Pertumbuhan pengusaha di Indonesia masih terbatas. Di dunia, jumlah ideal pengusaha adalah $2 \%$ dari total jumlah penduduk. Jumlah pengusaha di Indonesia sekitar 0,18 \% dari total jumlah penduduk Indonesia. Keterbatasan pertumbuhan pengusaha di Indonesia terhambat oleh tiga faktor, yaitu fasilitas, regulasi, dan insentif. Salah satu cara yang dilakukan pemerintah untuk mendorong perkembangan pengusaha adalah membangun incubator yang menghasilkan sinergi antara teknologi dan bisnis. Seluk beluk incubation technology (i-tech) dimulai dari invention dan innovation process, $i$-tech incubation program, i-tech partner, dan $i$ tech incubation process. Dalam i-tech incubation program, program inkubasi dimulai sejak preincubation, incubation, sampai pasca-incubation. Dalam pre-incubation, pemerintah melakukan sinergi kemitraan (workshop, Focus Group Discussion (FGD)), temu bisnis (technology pull, market pull). Pada proses inkubasi, pemerintah memfasilitasi mulai dari tempat (ruang, listrik, telepon, faksimile), trial produksi, training, mentoring, alpha test (uji konsumen), beta test (uji jual). Setelah inkubasi cukup dan pengusaha siap, pemerintah membantu aksesabilitas untuk produksi massal pascainkubasi. [5]

Menurut penulis, training pada proses inkubasi yang akan dilakukan dapat dilakukan melalui pembelajaran jarak jauh dengan bantuan teknologi informasi dalam setiap FGD. FGD disesuaikan dengan bidang usaha yang masih dalam satu bidang usaha. Contohnya kelompok bidang usaha batik yang terdiri dari pengusaha batik, distributor, supplier, perusahaan pembuat bandul, dingklik, gawangan, wajan, anglo, tepas, taplak, kemplongan, dan canting. [7] Melalui pembelajaran jarak jauh berbasis teknologi informasi, dapat ditekan biaya sehemat mungkin, terutama biaya untuk pelatihan. 


\section{PEMBELAJARAN JARAK JAUH}

Bagi sebagian orang, pembelajaran jarak jauh berhubungan dengan kelas tatap muka tradisional, mengintegrasikan sedikit video interaktif antar kampus yang terpisah secara geografis dari lokasi pelatihan. Sedangkan bagi orang lain, pembelajaran jarak jauh (distance learning) merupakan media yang sama sekali baru untuk instruksi, melainkan sebuah strategi pembelajaran baru yang berbeda dari ruang kelas dimana mahasiswa dan dosen berinteraksi melalui Internet dan disampaikan melalui video dan audio conferencing, kolaboratif antara siswa, atau berpartisipasi dalam kesempatan instruksi yang sinkron atau asinkron. [6]

Pendidikan jarak jauh dimulai pada tanggal 20 Maret 1728, ketika "iklan dalam Berita Boston Gazette : "Kaleb Phillips, Guru dari metode baru Tangan Pendek" sedang mencari siswa untuk pelajaran yang akan dikirim mingguan. [2]

\section{TEKNOLOGI INFORMASI}

Yang dimaksud dengan teknologi informasi adalah gabungan antara teknologi komputer dan teknologi telekomunikasi. Teknologi komputer adalah teknologi yang berhubungan dengan komputer, termasuk peralatan-peralatan yang berhubungan dengan komputer seperti printer, pembaca sidik jari, dan bahkan CD-ROM. [3]

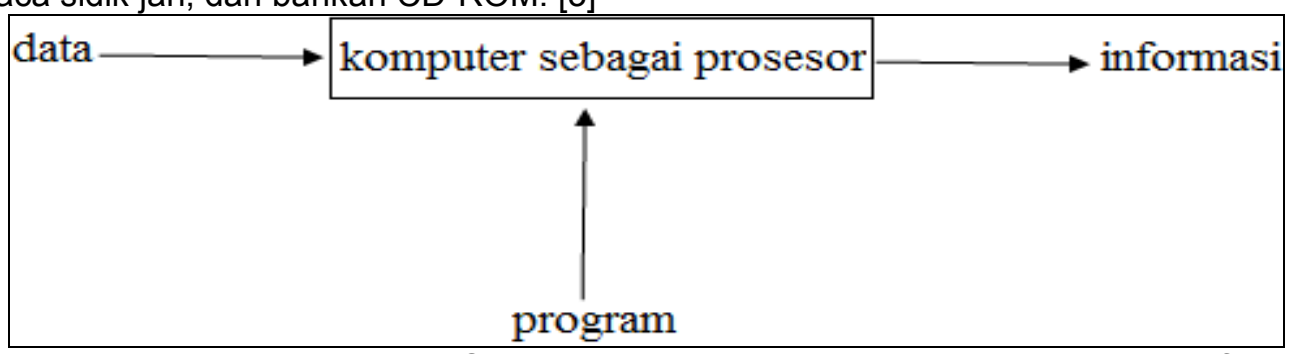

Gambar 1. Komputer Dikendalikan Oleh Program Untuk Memproses Data Menjadi Informasi [3]

Sedangkan, teknologi telekomunikasi atau disebut juga teknologi komunikasi merupakan teknologi yang berhubungan dengan komunikasi jarak jauh, seperti telepon, radio, televisi. Hal ini ditunjukkan oleh gambar 2 yang menjelaskan bahwa pentingnya peranan teknologi telekomunikasi sehingga setiap manusia di seluruh dunia dengan komputernya masing-masing dapat saling berkomunikasi melalui jaringan internet. [3]

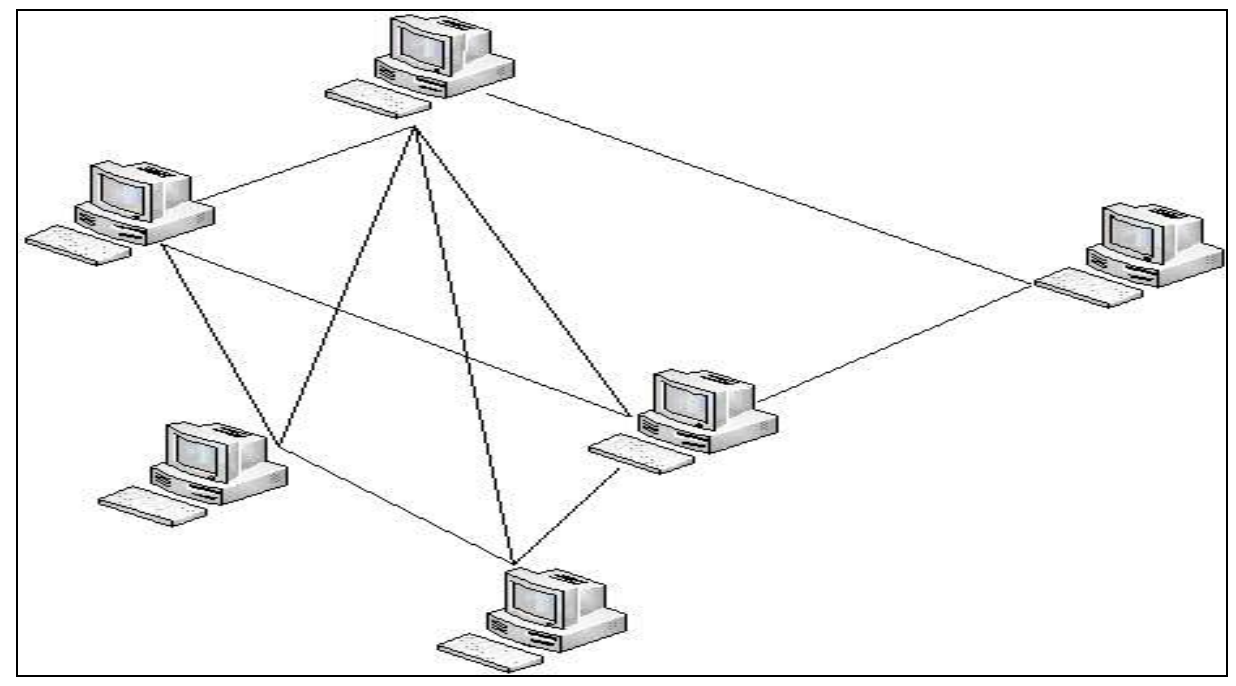

Gambar 2. Teknologi Telekomunikasi Menjadikan Komputer-Komputer Di Seluruh Dunia Dapat Saling Berkomunikasi. [3] 


\section{PEMBELAJARAN JARAK JAUH BERBASIS TEKNOLOGI INFORMASI YANG COCOK UNTUK KALANGAN ENTREPREUNER}

\subsection{Arsitektur Pembelajaran Jarak Jauh}

Seperti yang telah dikemukakan sebelumnya, bahwa bidang usaha yang akan mengimplementasikan pembelajaran jarak jauh ini adalah bidang usaha yang masih dalam satu kelompok bidang usaha. Pada gambar 3 menjelaskan bahwa aplikasi pembelajaran jarak jauh tersebut di-install ke komputer server dan diletakkan di kantor induk bidang usaha atau menyewa komputer server melalui sebuah perusahaan jasa penyedia layanan internet. Aplikasi pembelajaran jarak jauh pada komputer server tersebut akan diakses oleh semua client (para pengusaha) yang masih dalam satu kelompok bidang usaha, melalui piranti jaringan, misalnya komputer desktop melalui switch hub dengan perantara kabel LAN dan media protable (HP, laptop, PDA, smartphone, dan tablet PC) melalui jaringan wireless seperti hotspot.

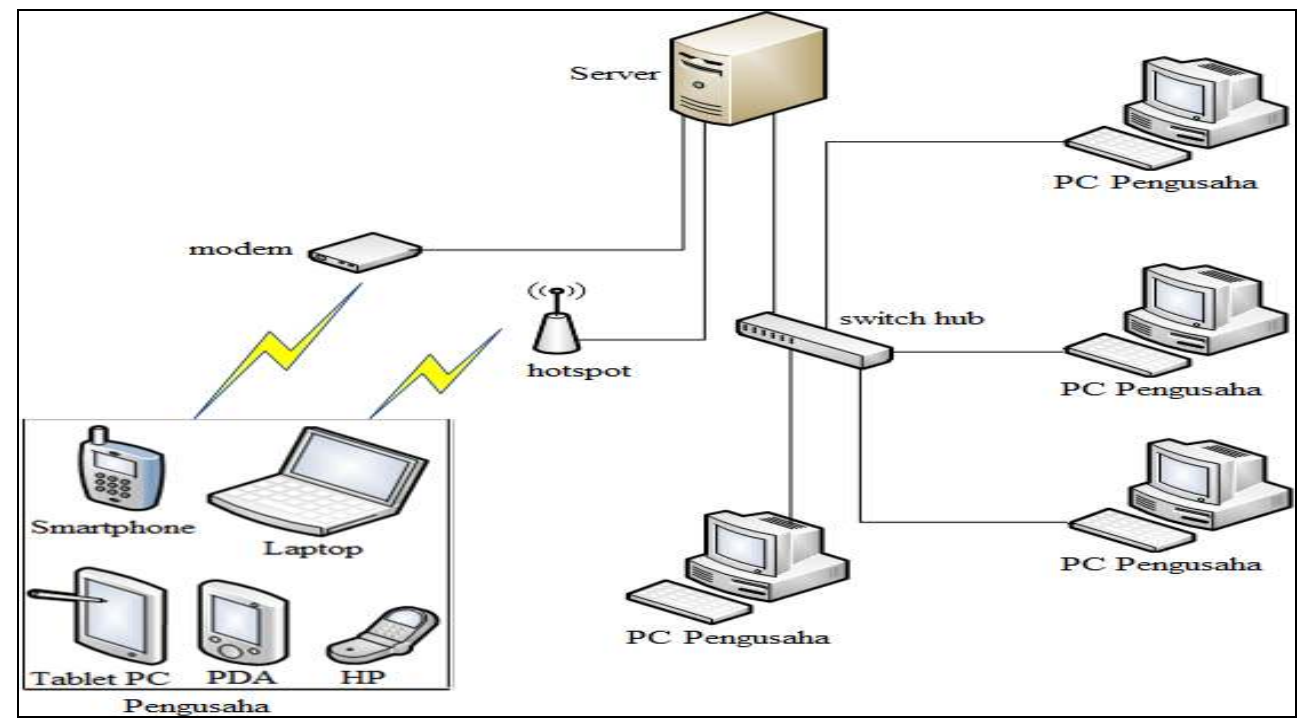

Gambar 3. Arsitektur Pembelajaran Jarak Jauh Dalam Satu Kelompok Usaha

\subsection{Jenis Pembelajaran Jarak Jauh}

Banyak sekali jenis pembelajaran jarak jauh, namun jenis pembelajaran jarak jauh yang cocok untuk para pengusaha, yaitu e-learning dan instant messaging. Berikut ini penjelasannya.

\subsubsection{E-learning}

E-learning pertama kali diperkenalkan oleh universitas Illionis di Urbana-Champaign dengan menggunakan sistem instruksi berbasis komputer (computer-assisted instruction) dan komputer PLATO. Sejak saat itu, perkembangan e-learning berkembang sejalan dengan perkembangan kemajuan teknologi. Pada tahun 1990 muncul CBT (Computer-Based Training) dengan bermunculan aplikasi e-learning untuk PC standlone yang disimpan ke dalam CD-ROM. Isi materi dalam CD-ROM tersebut berbentuk mov, mpeg-1, dan avi. Sejak tahun 1994, CBT muncul dalam bentuk paket-paket yang lebih menarik dan diproduksi secara massal. Pada tahun 1997 muncul LMS (Learning Management System), menggunakan koneksi internet. Kebutuhan akan informasi yang dapat diperoleh dengan cepat mulai dirasakan sebagai kebutuhan mutlak dan jarak serta lokasi bukanlah halangan lagi. Perkembangan LMS yang makin pesat membuat pemikiran baru untuk mengatasi masalah interoperability antar LMS yang satu dengan lainnya secara standar. Bentuk standar LMS dikeluarkan oleh AICC (Airline Industry CBT Commettee), IMS, IEEE LOM, ARIADNE, dsb. Mulai tahun 1999 sebagai tahun aplikasi e-learning berbasis web. Perkembangan LMS menuju aplikasi e-learning berbasis web berkembang secara total, baik untuk pembelajar (learner) maupun administrasi belajar mengajarnya. LMS mulai digabungkan dengan situs-situs informasi, majalah dan surat kabar. Melihat perkembangan e-learning dari dari masa ke masa yang terus berkembang mengikuti perkembangan teknologi, maka e-learning akan menjadi sistem pembelajaran masa depan. Alasan efektifitas dan fleksibilitas akan menjadi alasan utama. [1]. 
Beberapa LMS yang termasuk dalam kelompok open source adalah bodington (http://bodington.org/), claroline (http://www.claroline.net/), .LRN (http://dotlrn.org/users/), moodle (http://moodle.org/), OLAT (http://www.olat.org/public/index.html), dokeos (http://campus.dokeos.com/index.php), sakai (http://www.sakaiproject.org/), dan efront (http://www.efrontlearning.net/). [6].

Oleh karena itu, e-learning ini sangat cocok untuk pembelajaran jarak jauh bagi para pengusaha, terutama LMS yang termasuk dalam kelompok open source, karena bebas dikembangkan oleh siapapun secara gratis dan menghemat biaya, khususnya bagi pengusaha pemula.

\subsubsection{Instant Messaging}

Instan Messanging merupakan teks untuk berkomunikasi secara real-time seperti percakapan antar orang melalui internet. Saat ini, banyak Instan Messanging yang open source, seperti eBuddy, Yahoo Messenger, Pidgin, Skype, dan lain-lain. Beberapa kemampuan yang diberikan oleh instan messaging software, yaitu pesan instan, chatting, web link, video, gambar, suara, file, bicara, konten streaming, dan kemampuan mobile. [4].

Berdasarkan kemampuannya, penggunaan Instan Messanging yang open source dapat mendukung pembelajaran jarak jauh bagi para pengusaha, dengan menghemat biaya pembelian komputer server dan sewa gedung untuk kantor, serta hal ini yang akan melahirkan konsep e-office (electronic-office)

\section{KESIMPULAN}

Pembelajaran jarak jauh sangat bermanfaat sekali bagi para pengusaha, karena dapat menghemat biaya pelatihan. Dari kedua tipe pembelajaran jarak jauh di atas yang dapat menghemat biaya khususnya bagi para pemula adalah Instant Messaging karena dapat menghemat biaya pembelian komputer server dan sewa gedung kantor, hal ini yang akan melahirkan konsep e-office (electronic-office).

\section{DAFTAR PUSTAKA}

Edufiesta, 2010, "Sejarah Perkembangan E-learning", [on-line]: http://edufiesta.blogspot.com/2008/06/sejarah-perkembangan-e-learning.html, diakses pada tanggal 12 April 2012.

Holmberg, B., 2005, "The Evolution, Principles and Practices of Distance Education", Studien und Berichte der Arbeitsstelle Fernstudienforschung der Carl von Ossietzky Universität Oldenburg [ASF]. 11. Bibliotheks-und Informationssystem der Universitat Oldenburg.

Kadir, A., dan Triwahyuni, T. C., 2005, "Pengenalan Teknologi Informasi", Andi Publisher, Yogyakarta.

Khoiruddin, A. A., Idam, A. S., Humairo, L., and Amien, N., 2010, "The Use of Spark and OpenFire to Support Distance Learning", Proceeding of International Conference on Open Source for Higher Education, Sebelas Maret University, Solo, Indonesia, March 15th, 2010.

Kompas, 2011, "Inkubasi Teknologi Dorong "Entrepreneur" [on-line]: http:// bisniskeuangan.kompas.com/read/2011/04/13/17340051/Inkubasi.Teknologi.Dorong.Entrep eneur, diakses pada tanggal 12 April 2012.

Negash, S., Whitman, M. E., Woszczynski, A. B., Hoganson, K., and Mattord, H., 2008, "Handbook of Distance Learning for Real-Time and Asynchronous Information Technology Education", IGI Global.

Singgih, 2008, "Perlengkapan Batik Tradisional", [on-line]: http://cantingbatik.wordpress.com/2008/05/28/perlengkapan-membatik-tradisional/, diakses pada tanggal 12 April 2012. 